\title{
Household purchasing of cheap alcohol: Who would be most affected by minimum unit pricing?
}

\author{
OUREGA-ZOÉ EJEBU 1 , * \\ LYNDA MCKENZIE ${ }^{1}$ \\ ANNE LUDBROOK ${ }^{1}$ \\ ${ }^{1}$ Health Economics Research Unit (HERU), Institute of Applied Health Sciences, University of Aberdeen, \\ Scotland
}

\begin{abstract}
Minimum unit pricing of alcohol has been proposed as a more effective policy for reducing alcohol-related harms than general taxation. Growing international evidence points to its effectiveness in targeting high risk drinkers, but concerns about the impact on low risk drinkers and those on low incomes remain. This paper uniquely models the potential effect on both low risk and low income purchasers in a Scottish subsample of UK panel data from introducing a minimum unit price and addresses the impact of missing income data on the results. Weekly household purchases of cheap off-sales alcohol from Kantar Worldpanel (20082010) are analysed using Hausman-Taylor, Tobit and OLS models. Explanatory variables include economic and demographic characteristics of the households, average alcohol purchasing level for all off-sales alcohol, and characteristics of alcohol products purchased. The number of cheap alcohol units purchased are predicted by income group and purchasing level. Results indicate that the amount of cheap alcohol purchased is positively associated with the average purchasing level for all off-sales alcohol. Lower occupational group is associated with purchasing more units of cheap alcohol. Type of alcohol and purchasing alcohol on promotion are also highly significant. Predicted quantities of cheap alcohol purchased are not higher for the low-income group. Households in the top decile of alcohol purchasing level are predicted to purchase between 18 units of cheap alcohol weekly (low income) and 24 units (intermediate income). There was no evidence of bias due to missing income data. Minimum unit pricing for alcohol will have most impact on households purchasing the most alcohol, at all income levels. Restrictions on promotions should be considered as these are also associated with increased purchasing of cheap alcohol.
\end{abstract}

JEL classification: I12, I14, I18, D12, D18

Key words: alcohol purchase, minimum unit pricing, households, panel data, low-risk

\section{Introduction}

The relationships between alcohol prices, level of alcohol consumption and alcohol-related harms are well established (Chaloupka et al., 2002, Academy of Medical Sciences 2004, Wagenaar et al., 2009, Wagenaar et al., 2010, Elder et al., 2010, Giesbrecht et al., 2016).

* Correspondence to: Ourega-Zoé Ejebu, Health Economics Research Unit (HERU), University of Aberdeen, Institute of Applied Health Sciences, Polwarth Building, Foresterhill, Aberdeen AB25 2ZD, Scotland. E-mail: oejebu@abdn.ac.uk.

Published: Online April 2018. dx.doi.org/10.5617/njhe.4878 
Raising prices is recognised as an effective and cost-effective policy for addressing alcohol misuse (Chaloupka et al., 2002, Anderson et al., 2009, Wagenaar et al., 2009, Wagenaar et al., 2010, Elder et al., 2010). The mechanism for achieving price increases has come under increasing scrutiny, with minimum unit pricing (MUP) for alcohol proposed as a potentially more effective policy than increases in taxation (Gillan and Macnaughton, 2007, Scottish Government, 2012).

Modelling of Swedish data (Gruenewald et al., 2006) has shown that price increases for the lowest cost alcohol produces greater reductions in purchasing that an equivalent increase applied to all alcohol. Heavier drinkers might respond to any general price increase due to taxation by 'trading down' and purchasing cheaper alternative alcohol products (Hobday et al., 2016). Evidence for the effectiveness of MUP has accumulated, with recent research relating to reduction in alcohol consumption (Stockwell et al., 2012a, Sharma et al., 2014, Holmes et al., 2014) and alcohol-related harms (Stockwell et al., 2012a, Stockwell et al., 2017).

Although taxation could be efficient in increasing prices and reducing alcohol consumption, MUP circumvents retailers' ability to absorb tax increases on lower priced products (Ally et al., 2014). However, policy makers remain concerned that targeting cheap alcohol may penalise low risk drinkers, with UK Government ministers not convinced that MUP would "reduce problem drinking without penalising all those who drink responsibly" (Home Office, 2013). This was despite studies which suggest that low risk drinkers are least likely to be affected, given their relatively low alcohol consumption and tendency not to purchase the type of products targeted by MUP (Hunt et al., 2011, Black et al., 2011, Crawford et al., 2012). Household purchasing of alcohol at levels consistent with low alcohol consumption is associated with a lower predicted probability of purchasing cheap alcohol (Ludbrook et al., 2012). This latter finding is based on records of alcohol purchasing over a two-week period from the UK Expenditure and Food Survey. These data may underrepresent the number of households purchasing alcohol when compared with data collected over a longer period. More recent studies also support the view that MUP has least impact on low risk drinkers (Sharma et al., 2014, Holmes et al., 2014).

Policy makers could also be concerned if MUP disproportionately affected low income groups, but research again suggests that MUP is only likely to impact people on low incomes if their alcohol consumption is excessive (Crawford et al., 2012, Ludbrook et al,. 2012, Holmes et al., 2014). Only one report has suggested that the least well-off might face a higher burden (Leicester, 2011); this was based on estimating the impact of MUP as a percentage of food budgets, assuming that consumers did not change their purchasing behaviour. All other studies have accounted for the reduction in consumption or purchasing induced by a price increase.

Most studies have used cross-sectional data, providing only a snapshot of consumer behaviour. This may overestimate the number of people not buying alcohol at all if they do not buy regularly and this is not observed in the survey period. Similarly, heavy purchasing may be overestimated if consumers are observed stockpiling alcohol which they consume over a longer period. Longitudinal (panel) data overcomes these issues to some extent by observing purchasing behaviour over a longer period and across the same individuals. Two studies have used panel data from household scanner data (Leicester, 2011, Sharma et al., 2014). Leicester (2011) does not model any changes in consumption, even though this is the most likely response by consumers, and income values were missing for more than $20 \%$ of the households in the panel with no discussion of how this might impact on the results. Sharma et al. (2014) found that impact was small on lower level purchasers, but do not report results by income. The study by Holmes et al. (2014) created a pseudo-panel from 
multiple cross-section observations using self-reported alcohol consumption, which avoids the need to aggregate across time.

This paper aims to identify the impact of a MUP for alcohol on both low risk and low income purchasers in Scotland. It further contributes to the debate by identifying the type of households which will be most affected by the introduction of MUP, in terms of level of off-sales alcohol units purchased per adult in the household and income groups. This is the first paper to address both issues simultaneously using panel data to overcome concerns about the use of cross-section data. The analysis is based on the purchasing behaviour of households over an extended period (up to three years) which enables a better representation of typical purchasing patterns. The issue of missing income data, which has been a feature of household scanner data, is also addressed. The results confirm that purchasing cheap alcohol is most related to purchasing relatively higher quantities of alcohol, across all household decile. This is both in terms of the probability of purchasing cheap alcohol and the amount of cheap alcohol purchased. The exclusion of households with missing income data does not appear to bias these results.

\section{Data and variables}

Data were obtained from the market research company, Kantar Worldpanel (KWP) database; a panel of approximately 25,000 UK households recruited using stratified sampling methods partly based on UK Census returns to achieve national representation. Participants are rewarded for their time in the panel with high-street vouchers. Regular compliance and quality control checks are undertaken. A subset of 3076 Scottish households was used; 2185 joined the panel before the start of the first study week, the remainder joined over the three years. The data covers three years (2008-2010) or 156 weeks. Households were in the panel for an average of 117 weeks (range 1 to 156). At least one purchase of an alcohol product was made by 2671 households (87\%); 405 households had no record of alcohol purchase.

Households recruited by KWP are provided with a handheld scanner to record daily purchases made by all members of the household for items taken home for consumption, by scanning the product's barcode and uploading the information using a PC. Households provide till receipts as a means of providing price information. Since only items purchased and taken home are recorded, only off-trade alcohol is included; i.e. alcohol bought in supermarkets or other shops for consumption off the premises. Off-trade sales of alcohol accounted for between 66\% (2008) and 69\% (2010) of total alcohol sales by volume in Scotland (NHS Health Scotland, 2014a) and are the focus of MUP legislation. Household characteristics including income, occupation, age and household composition were also recorded in Kantar database. Only one observation per household was available for each demographic variable.

Alcohol purchases were recorded daily. A detailed product description identified the type and quantity of alcohol, amount spent, and whether the purchases were on promotion. Volume was combined with alcoholic strength to calculate units of alcohol (1 unit $=10 \mathrm{ml}$ pure alcohol). For many products, the alcohol by volume (ABV) was in the product description. Where no ABV was identifiable, standard ABV values were used (e.g. 40\% for whisky). Price per unit of alcohol was calculated for each purchase using the amount spent and adjusted to 2011 values, using the Consumer Price Index (CPI) (Office for National Statistics, 2012). The dependent variable is the number of cheap alcohol units purchased weekly, defined as less than $£ 0.50$ ( $\$ 0.62, € 0.58$ ) per unit, which corresponds to the threshold value the Scottish government selected for their legislation and is to be implemented in May 2018. 
The data were prepared for panel analysis by aggregating daily records to weekly purchases, creating a unique time identifier (week number). This resulted in a usable number of 75,286 weeks of alcohol purchases. Excluding the 405 households with no record of alcohol purchases, the data comprised 257,735 weeks of grocery purchases of which 75,286 weeks (29\%) had alcohol purchases recorded and 182,449 weeks had zero alcohol purchases. Allowing for missing data among different demographic variables, 161,147 observations were available for analysis. Most of the missing data was due to household income not being recorded for 541 households. The effect of missing data on the results was explored, as described in section 4.

A variable was created to categorise households according to the average amount of off-sales alcohol purchased. The household average number of units of alcohol purchased per adult per week was grouped into deciles. This value was estimated using all weeks with grocery purchase records, including those weeks with no alcohol purchase. This allows for alcohol not being consumed in the same week it was purchased. However, the extent of higher levels of alcohol consumption is likely to be underestimated because on-sales could not be included and the allocation of consumption between individuals within the household cannot be considered.

Household income was reported by household respondents in 7 bands of $£ 10,000$ and an eighth band of over $£ 70,000$. Given that households were self-reporting their gross income, there was a potential for misallocation of actual income that was close to a threshold between bands. This was reduced by creating 3 groups for the analysis (low (below $£ 20,000)$, intermediate ( $£ 20,000-£ 49,000)$ and high ( $£ 50,000$ and above)). When compared with gross household income deciles for 2010, the low income group corresponds to approximately the lowest third of UK household incomes (i.e. the cut off lies within the 4th decile) and the highest income group has a boundary within the 8th income decile therefore covering more than $20 \%$ of highest incomes. The median UK income is in the intermediate band.

The Kantar dataset included a variable for household occupation with six categories. Five of the six categories refer to the type of occupation; a sixth group covers all nonworking categories (i.e. students, unemployed and pensioners). Given the potential wide disparities within this population, in terms of income, purchasing habits and preferences for alcohol, the sixth occupational class was not included in the regressions. However, the effect of the sixth occupational class on the results was explored, as described in section 4 . The remaining five occupational classes were merged into 3 occupational groups (higher managerial and professional, intermediate, and routine and manual) which may capture purchasing trends not identifiable by income variables. Acorn (A Classification of Residential Neighbourhood) category was also included to consider any influence of residential area. The 56 Acorn categories in the Kantar dataset were collapsed into five categories (wealthy achievers, urban prosperity, comfortably off, moderate means and hard pressed) (Acorn, 2013). Age of the head of household and households with young children (i.e. children younger than 5 years old) were also included in the model. Alcohol consumption may vary with age and household composition. Family responsibilities might reduce alcohol consumption and hence purchasing. A promotion variable was included to control for the effect of any special offers or discounts on alcohol purchasing. Survey year was included to control for national trends that may influence aggregate purchasing levels.

Other alcohol-related variables included in the analysis were average weekly alcohol expenditure (in pounds Sterling) and type of alcohol as provided by Kantar (beer or lager; cider; flavoured alcoholic beverages (FABs or alcopops); wine; other wines (sparkling and fortified wines); and spirits). Type of alcohol is a categorical variable, taking the value 1 if any of that type of alcohol was purchased, and 0 otherwise. The alcohol products cover all 
the type of alcoholic drinks that can be purchased in Scotland. Zero purchase weeks was also included, i.e. the proportion of a household's shopping weeks where no alcohol was purchased. It provides information on the effects of frequency on alcohol purchases.

\section{Methods}

The econometric model uses panel data in which observations of the same households are followed over a three-year period and there is more than one observed week of shopping per household. Besides, in the KWP data, socio-demographic variables are only recorded once in the last survey year (i.e. 2010). Hence, there is a possibility that a conventional approach using ordinary least squares (OLS) regression may produce biased estimates for time-invariant explanatory variables (i.e. household characteristics which are only recorded once for each household or which do not vary over time). The use of a fixed effects (FE) model to overcome this problem would imply that time-invariant explanatory variables (e.g. household income, occupation, gender, age, Acorn and alcohol purchase level among others) cannot be estimated.

A Hausman-Taylor (HT) regression is a more flexible approach, and is the preferred model in this study. The HT estimator is an instrumental variable estimator that enables the coefficients of time-invariant explanatory variables in panel data to be estimated. It combines elements of both random effects (RE) and fixed effects (FE) estimations. HT assumes that some of the explanatory variables are correlated with the unobserved random individual-level effects: such explanatory variables are endogenous. It also assumes that none of the explanatory variables are correlated with the idiosyncratic errors: explanatory variables that are not correlated with either error terms are exogenous.

HT model corrects for endogeneity of time-invariant explanatory variables by using individual means of strictly exogenous explanatory variables as instruments (Baltagi et al., 2003, Cameron and Trivedi, 2009). Thus, the empirical application required the distinction between the explanatory variables which are uncorrelated with the unobserved random individual-specific effects (exogenous explanatory variables); and the explanatory variables which are potentially correlated with the unobserved random individual-specific effects (endogenous explanatory variables). The choice of strictly exogenous explanatory variables is a testable hypothesis. Failure to reject the null hypothesis $\left(\mathrm{H}_{0}\right)$ of instrument validity implies the instruments are legitimate. The methods additionally distinguishes between time-varying and time-invariant explanatory variables. The HT equation is specified as follows:

$$
\tilde{y}_{i t}=\widetilde{\boldsymbol{x}}_{1 i t}^{\prime} \boldsymbol{\beta}_{1}+\widetilde{\boldsymbol{x}}_{2 i t}^{\prime} \boldsymbol{\beta}_{2}+\widetilde{\boldsymbol{w}}_{1 i}^{\prime} \boldsymbol{\gamma}_{1}+\widetilde{\boldsymbol{w}}_{2 i}^{\prime} \boldsymbol{\gamma}_{2}+\tilde{\alpha}_{i}+\tilde{\varepsilon}_{i t}
$$

$x$ and $w$ are explanatory variables; $w$ denotes time-invariant explanatory variables, $x$ denotes time-varying explanatory variables; and $\varepsilon_{i t}$ the idiosyncratic error term.

Results from OLS and Tobit random effect (RE) regressions are also reported for comparison purposes. The latter model accounts for the panel structure of the data, but does not correct for the endogeneity of variables, since all variables are assumed to be uncorrelated with the unobserved individual-specific effect $\alpha_{i}$ (Cameron and Trivedi, 2009). Tobit RE regression also provides consistent estimates when the sample contains both positive and zero values for cheap alcohol purchased. In the Tobit RE model, the dependent variable can be considered as a latent variable for the demand for cheap alcohol units. Zero cheap units can be interpreted as a case where there may be demand for cheap alcohol but no purchase of cheap alcohol was made. A transformation was applied to the Tobit RE model, such that the dependent variable was expressed in its logarithm form. This enables the sampling distribution of the dependent variable to be corrected for skewness and 
converge to normality (Cameron and Trivedi, 2009). To avoid any loss of the zero observations, we computed a formula such that values of zeros were very close to zero (Cameron and Trivedi 2009). In addition, Tobit RE model was used for post-estimations to obtain predicted probabilities and predicted purchased quantities.

Sensitivity analyses included omitting variables potentially correlated with each other (income, occupation, Acorn categories) and alcohol products. The effect of missing income data for 541 households was also explored by comparing the distribution of alcohol purchase levels for households with and without income data; running the HT model excluding income on all households and comparing results with a sub-sample excluding households with missing income.

\section{Results}

\subsection{Descriptive statistics}

Table 1 provides the basic descriptive statistics. These are presented for the whole sample and 3 subgroups of households: households who never purchased alcohol; households who purchased alcohol but never cheap, and households whose purchases included both cheap and non-cheap alcohol. Those who never purchased alcohol, and were dropped from the analysis, were more likely to be younger, female, have young children, and have lower incomes; which would be consistent with patterns of alcohol consumption. Table 1 also shows the descriptive for the sample used in the main estimation after allowing for missing values. Overall, the frequency distribution of the whole and estimation samples are relatively similar. There is a slight variation in frequency distribution amongst younger households $(17>30)$, as well as income groups (low and intermediate) and occupation (intermediate, and routine and manual).

Table 2 provides the statistics for alcohol-related variables of the whole sample and for the subgroups of households who purchased alcohol as in Table 1. The highest purchasing decile, decile 10, contains only households purchasing more than 14 units per person per week, whilst decile 9 contains households purchasing above and below this level. UK Chief Medical Officers' current advice on low risk drinking recommends no more than 14 units of alcohol per week, applied equally to men and women (Department of Health, 2016). The relatively high percentage of weeks with zero purchases is an indicator of the potential of misclassifying infrequent purchasers as zero purchasers when observing shorter time periods. The average number of units and cheap units purchased per week by income group and survey year are also reported in Table 2 . The weekly mean is provided both for all weeks observed (including weeks when households purchased groceries but no alcohol) and for only weeks where alcohol was purchased.

The summary statistics in Table 2 indicate a positive and significant $(\mathrm{p}<0.000)$ income gradient for the mean units of all alcohol purchased, such that high-income households purchased the most units. Considering cheap alcohol, the gradient is also positive and significant $(\mathrm{p}<0.000)$ for the mean of cheap units including zero purchase weeks. However, the income gradient is negative and significant $(\mathrm{p}<0.000)$ when zero purchase weeks are excluded. This suggests a different purchasing pattern, such that lowincome households had more zero purchase weeks. The mean units purchased in each survey year decreased slightly from 2008 to 2010 for all alcohol and cheap alcohol alike. 


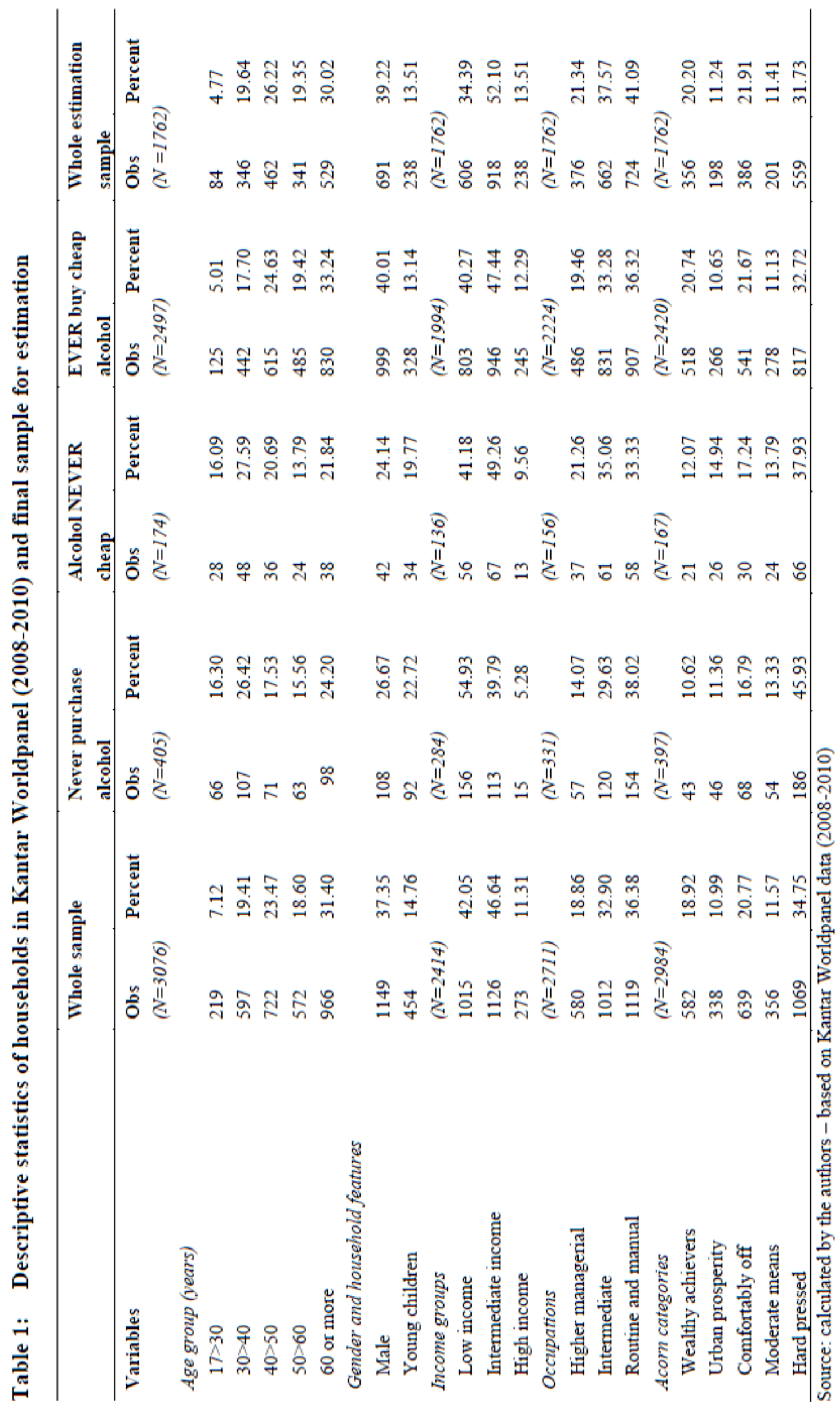




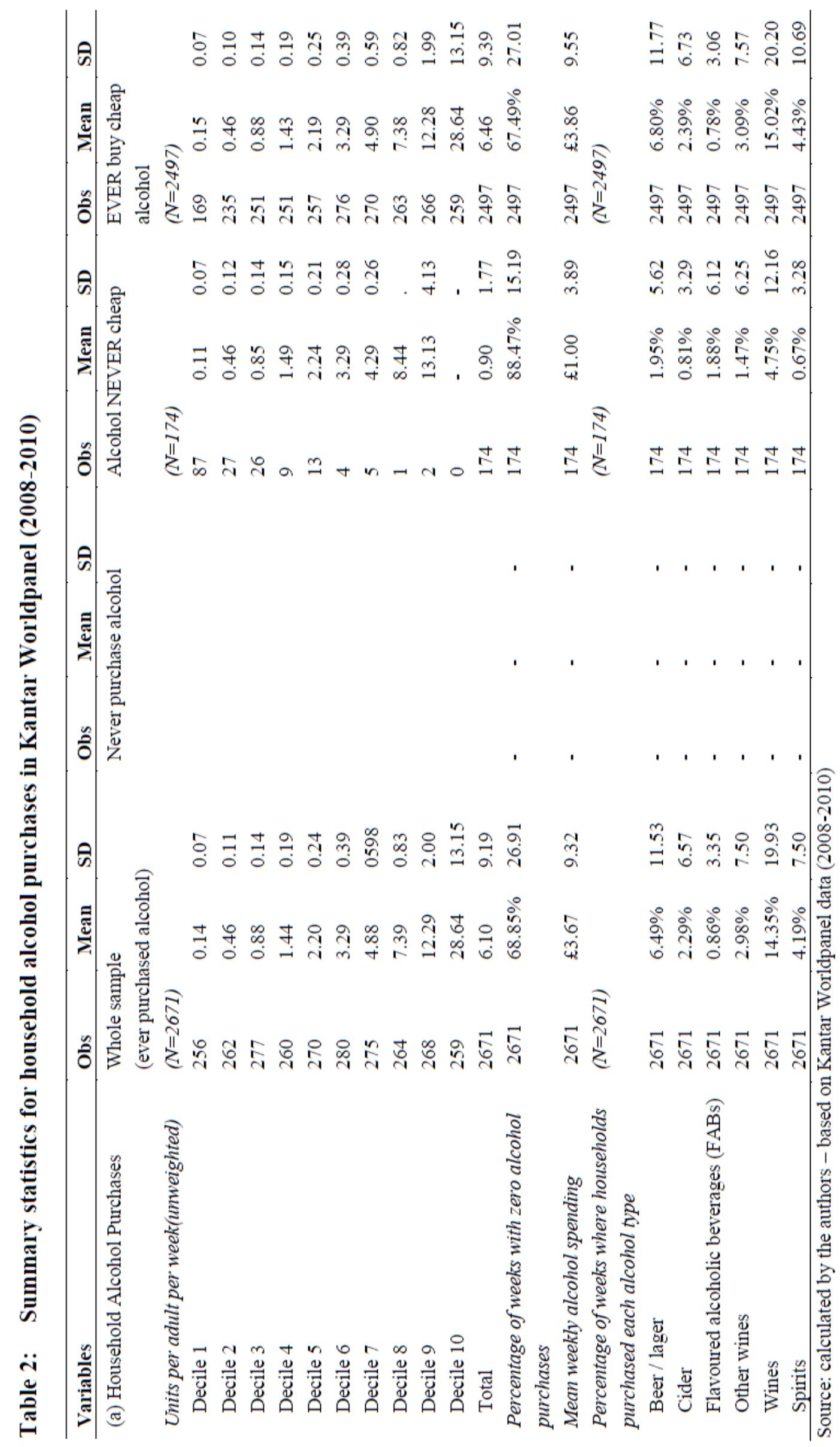




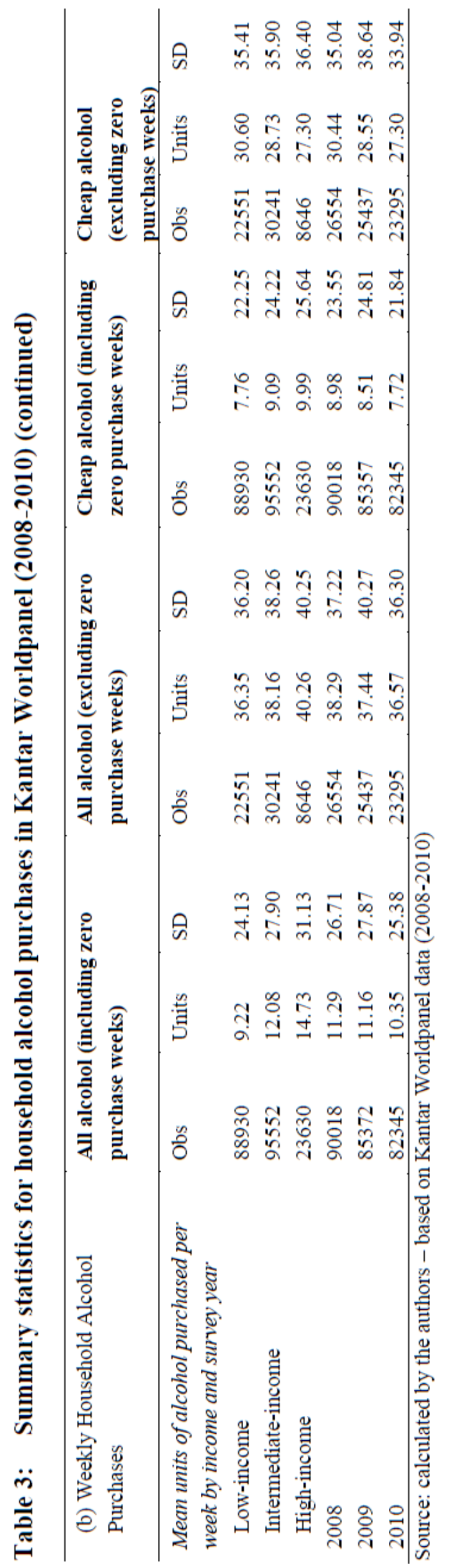




\subsection{Econometric analyses of cheap alcohol units purchased}

Table 3 presents the estimates of OLS, Tobit RE and Hausman-Taylor (HT) regressions. The HT specification is supported as the null hypothesis $\left(\mathrm{H}_{0}=\right.$ over-identifying restrictions are valid) failed to be rejected ( $p=0.5714>0.05)$, indicating the validity of the instrumental variables. Comparison of the results with Tobit RE and OLS regressions illustrates how the ignoring panel structure and endogeneity result in overestimating the importance of certain explanatory variables.

The relationship between cheap alcohol units and purchasing level in the HT model is positive and statistically significant for deciles 4 and above; households with the highest purchasing levels for all alcohol purchase the most units of cheap alcohol. Whilst low income is positive and significant in the OLS (1\% level) and Tobit RE (10\% level only) models, income is positive but not significant in the HT model. This change may be attributed to the potential effects of the panel structure and the endogeneity of alcohol products and expenditure, which are ignored by both OLS and Tobit RE models respectively. OLS tend to produce biased and inconsistent estimates of time-invariant variables when using a panel and in the presence of endogeneity in the model (Cameron and Trivedi, 2009). Results suggest that variation over same households and variation over time may have been better captured in the HT than in the OLS model, and that by ignoring the panel structure, OLS may have overestimated the importance of income variables, among others. Results from the HT indicate that routine and manual, and intermediate occupations purchase significantly more cheap alcohol compared to higher occupational groups.

Apart from flavoured alcoholic beverages (FABs), purchases of all other alcohol types are significantly associated with an increase in cheap alcohol purchases when compared with the base category, wine. Alcohol expenditure, promotion, and zero purchase weeks are significantly and positively associated with the demand for cheap alcohol units. Survey year is statistically significant with fewer cheap units of alcohol purchased in 2009 and 2010 respectively, as compared to 2008. Whilst Acorn categories, gender and age have some significant coefficients in the OLS and Tobit RE specifications, they are insignificant in the HT regression.

Alternative models were estimated to ensure the robustness of our results ${ }^{1}$. Firstly, HT was run without 'income', 'occupation', 'Acorn', and 'alcohol products' respectively. In each of the 4 specifications, signs, magnitude and significance of the coefficients are mostly unaffected, compared to the preferred HT model. The exception is the specification without 'occupation', where low $\left(\beta_{1}=1.756\right)$ and intermediate $\left(\beta_{2}=1.348\right)$ income variables were positively and significantly associated with purchase of cheap alcohol units at the $5 \%$ and $10 \%$ levels, respectively.

The last specification simultaneously excluded 'occupation' and 'Acorn categories', based on the assumption of collinearity between these variables and income; and potentially causing the low-level of significance of income variable. Overall, the results were also consistent with the preferred HT model. Noticeably, there was a change in the significance of income variables: low $\left(\beta_{3}=2.027\right)$ and intermediate $\left(\beta_{4}=1.540\right)$ incomes were positively and significantly associated with purchases of cheap alcohol units at the $5 \%$ level. This suggests that Acorn categories, occupation and income are potentially correlated. This is confirmed in the correlation matrix which revealed that most of these aforementioned variables are significantly correlated at the $1 \%$ level $(\mathrm{p}<0.000)^{2}$.

Results of the HT model indicate that the effect of income on purchase of cheap alcohol units is more evident when occupation and Acorn are not controlled for. This may

\footnotetext{
${ }^{1}$ Results not displayed but available on request from the authors.

${ }^{2}$ Results not displayed but available on request from the authors.
} 
suggest that Acorn and occupation have diluted the effect of income or that the role of income has less importance once occupation and neighbourhood (Acorn) are accounted for. The non-significance of income may also be explained by the fact that there is usually little variation of income when considering occupation and neighbourhood: this implies that one would expect that on average low (high) income households tend to live in poorest (richest) neighbourhood and tend to belong to lowest (highest) occupational class. Finally, from an empirical perspective, it is also common for variables conveying the same type of information, such as social status or purchasing power, to act as a proxy for each other and provide more information separately, rather than jointly.

\section{Missing income data and excluded occupation}

Income data was missing for $20.3 \%$ of the households who purchased alcohol (541/2671). The percentage $(21.8 \%$ 38/174) was similar for those who never bought cheap alcohol and those who did buy cheap alcohol (20.1\% 503/2497). The distribution of alcohol purchase levels for households with and without missing income data was similar (Pearson $\operatorname{chi}^{2}(9)=$ 11.15; $\operatorname{Pr}=0.265$ (Table 4)).

When HT estimation was run without the income variable, the results were similar in terms of signs, significance level and magnitude of coefficients. Restricting the estimation without the 'income variable' to households for which income data was available also produced similar findings. Results for households without income data differed only in having slightly more insignificant coefficients (occupation, $4^{\text {th }}$ and $5^{\text {th }}$ household alcohol deciles); the coefficients for household alcohol decile had the same level of significance and similar size compared to the preferred HT model.

Additional sensitivity analyses investigated the effect of the sixth occupational class (unemployed, not economically active, pensioners and students) on cheap alcohol purchase. This variable represented 9\% of households who purchased alcohol (237/2671). Firstly, we ran the HT model for this occupational class only; the second model included the sixth occupational class as an explanatory variable; whilst the last model controlled for all variables including the sixth occupational class amongst the observations. With the exception of household alcohol deciles 4 and 5 which were not significant in the first model (i.e. occupational class 6 only), other results were consistent such that coefficients' signs, magnitude and significance were similar to the preferred HT model (results available on request). 
Table 3: OLS, Tobit RE and Hausman-Taylor (HT) regressions for units of cheap alcohol purchased

\begin{tabular}{|c|c|c|c|}
\hline \multirow[b]{2}{*}{ Control variables } & \multicolumn{3}{|c|}{ Weekly units of cheap alcohol } \\
\hline & OLS & Tobit RE & HT \\
\hline Household alcohol decile 2 (base: Household & $-0.102 * * *$ & $0.589 * * *$ & 0.854 \\
\hline alcohol decile 1) & {$[0.028]$} & {$[0.083]$} & [1.118] \\
\hline \multirow[t]{2}{*}{ Household alcohol decile 3} & $-0.194 * * *$ & $0.787 * * *$ & 1.408 \\
\hline & {$[0.042]$} & {$[0.082]$} & [1.145] \\
\hline \multirow[t]{2}{*}{ Household alcohol decile 4} & -0.026 & $1.042 * * *$ & $2.485^{* *}$ \\
\hline & [0.057] & {$[0.081]$} & [1.196] \\
\hline \multirow[t]{2}{*}{ Household alcohol decile 5} & $-0.269 * * *$ & $1.101 * * *$ & $3.144 * *$ \\
\hline & {$[0.077]$} & {$[0.081]$} & [1.278] \\
\hline \multirow[t]{2}{*}{ Household alcohol decile 6} & $-0.317 * * *$ & $1.230 * * *$ & $4.094 * * *$ \\
\hline & [0.099] & [0.082] & [1.395] \\
\hline \multirow[t]{2}{*}{ Household alcohol decile 7} & -0.215 & $1.302 * * *$ & $5.925 * * *$ \\
\hline & [0.133] & {$[0.085]$} & [1.642] \\
\hline \multirow[t]{2}{*}{ Household alcohol decile 8} & -0.273 & $1.254 * * *$ & $7.430 * * *$ \\
\hline & [0.167] & {$[0.091]$} & [1.938] \\
\hline \multirow[t]{2}{*}{ Household alcohol decile 9} & $0.374 *$ & $1.109 * * *$ & $10.204 * * *$ \\
\hline & {$[0.224]$} & {$[0.100]$} & {$[2.390]$} \\
\hline \multirow[t]{2}{*}{ Household alcohol decile 10} & $8.490 * * *$ & $0.828 * * *$ & $21.556 * * *$ \\
\hline & [0.339] & [0.113] & [3.032] \\
\hline \multirow[t]{2}{*}{ Low income (base: High income) } & $1.421 * * *$ & $0.095^{*}$ & 1.096 \\
\hline & {$[0.120]$} & {$[0.050]$} & [0.867] \\
\hline \multirow[t]{2}{*}{ Intermediate income } & $0.878 * * *$ & 0.019 & 0.957 \\
\hline & {$[0.113]$} & {$[0.044]$} & {$[0.756]$} \\
\hline Routine and manual (base: Higher and & $1.476^{* * *}$ & 0.028 & $1.949 * * *$ \\
\hline professional) & {$[0.087]$} & {$[0.040]$} & {$[0.663]$} \\
\hline \multirow[t]{2}{*}{ Intermediate } & $1.050 * * *$ & $0.078^{* *}$ & $1.421^{* *}$ \\
\hline & {$[0.082]$} & {$[0.038]$} & {$[0.651]$} \\
\hline \multirow[t]{2}{*}{ Beer and lager (base: Wine) } & $8.612 * * *$ & $2.527 * * *$ & $8.285 * * *$ \\
\hline & {$[0.314]$} & {$[0.021]$} & {$[0.152]$} \\
\hline \multirow[t]{2}{*}{ Cider } & $11.480 * * *$ & $2.647 * * *$ & $7.647 * * *$ \\
\hline & {$[0.478]$} & {$[0.034]$} & {$[0.250]$} \\
\hline \multirow[t]{2}{*}{ FABs } & $-2.332 * *$ & $1.977 * * *$ & $-2.712 * * *$ \\
\hline & [1.125] & {$[0.079]$} & {$[0.596]$} \\
\hline \multirow[t]{2}{*}{ Other wines } & $8.397 * * *$ & $2.693 * * *$ & $4.990 * * *$ \\
\hline & {$[0.460]$} & {$[0.030]$} & {$[0.220]$} \\
\hline \multirow[t]{2}{*}{ Spirits } & $14.321 * * *$ & $3.055^{* * *}$ & $12.431 * * *$ \\
\hline & {$[0.412]$} & {$[0.025]$} & {$[0.180]$} \\
\hline \multirow[t]{2}{*}{ Alcohol expenditure } & $1.677 * * *$ & $0.077 * * *$ & $1.677 * * *$ \\
\hline & {$[0.032]$} & {$[0.001]$} & {$[0.004]$} \\
\hline \multirow[t]{2}{*}{ Promotion } & $3.374 * * *$ & $1.686 * * *$ & $4.751 * * *$ \\
\hline & {$[0.377]$} & {$[0.016]$} & [0.115] \\
\hline \multirow[t]{2}{*}{ Zero weeks (\%) } & $-0.017 * * *$ & $-0.030 * * *$ & $0.149 * * *$ \\
\hline & {$[0.004]$} & {$[0.001]$} & {$[0.037]$} \\
\hline
\end{tabular}

Robust standard errors in brackets. Significance levels: ${ }^{* *} \mathrm{p}<0.01,{ }^{* *} \mathrm{p}<0.05,{ }^{*} \mathrm{p}<0.10 .118,558$ leftcensored observations. 42,589 uncensored observations. 
Table 3: $\quad$ OLS, Tobit RE and Hausman-Taylor (HT) regressions for units of cheap alcohol purchased (continued)

\begin{tabular}{|c|c|c|c|}
\hline \multirow[b]{2}{*}{ Control variables } & \multicolumn{3}{|c|}{ Weekly units of cheap alcohol } \\
\hline & OLS & Tobit RE & HT \\
\hline \multirow{2}{*}{ Year of purchase 2009 (base: 2008) } & $-0.556 * * *$ & $-0.105 * * *$ & $-0.544 * * *$ \\
\hline & {$[0.080]$} & {$[0.014]$} & {$[0.072]$} \\
\hline \multirow[t]{2}{*}{ Year of purchase 2010} & $-1.055 * * *$ & $-0.190 * * *$ & $-1.013 * * *$ \\
\hline & [0.073] & [0.015] & {$[0.076]$} \\
\hline \multirow[t]{2}{*}{ Hard pressed (base: Wealthy achievers) } & $0.398 * * *$ & -0.013 & 0.622 \\
\hline & {$[0.076]$} & {$[0.040]$} & {$[0.677]$} \\
\hline \multirow{2}{*}{ Moderate means } & $0.894 * * *$ & 0.043 & 0.753 \\
\hline & {$[0.151]$} & {$[0.052]$} & {$[0.872]$} \\
\hline \multirow[t]{2}{*}{ Comfortably off } & $0.961 * * *$ & $0.076^{*}$ & 0.927 \\
\hline & [0.091] & [0.041] & [0.694] \\
\hline \multirow[t]{2}{*}{ Urban prosperity } & $-0.611 * * *$ & -0.062 & -0.463 \\
\hline & [0.119] & {$[0.050]$} & {$[0.855]$} \\
\hline \multirow[t]{2}{*}{ Household with young children } & 0.033 & -0.007 & 0.577 \\
\hline & {$[0.091]$} & {$[0.048]$} & {$[0.790]$} \\
\hline \multirow[t]{2}{*}{ Male (base: Female) } & 0.034 & -0.033 & 0.200 \\
\hline & {$[0.068]$} & {$[0.029]$} & {$[0.485]$} \\
\hline \multirow[t]{2}{*}{ Age 30-40 (base: Less than 30) } & $-0.183 *$ & 0.067 & 0.613 \\
\hline & {$[0.106]$} & {$[0.086]$} & {$[1.480]$} \\
\hline \multirow[t]{2}{*}{ Age 40-50 } & $-0.201 *$ & 0.072 & 1.148 \\
\hline & [0.109] & {$[0.084]$} & {$[1.440]$} \\
\hline \multirow[t]{2}{*}{ Age 50-60 } & $0.245^{*}$ & 0.072 & 1.853 \\
\hline & {$[0.126]$} & {$[0.086]$} & [1.485] \\
\hline \multirow[t]{2}{*}{ Age 60 and more } & $-0.614 * * *$ & 0.065 & 0.811 \\
\hline & {$[0.110]$} & {$[0.084]$} & [1.435] \\
\hline \multirow[t]{2}{*}{ Constant } & -0.016 & $-0.846 * * *$ & $-18.344 * * *$ \\
\hline & [0.409] & [0.154] & [4.004] \\
\hline \multirow[t]{2}{*}{ Sigma u } & & $0.492 * * *$ & \\
\hline & & {$[0.011]$} & \\
\hline \multirow[t]{2}{*}{ Sigma e } & & $1.520 * * *$ & \\
\hline & & {$[0.006]$} & \\
\hline Observations & 161,147 & 161,147 & 161,147 \\
\hline R-squared & 0.751 & & \\
\hline Rho & & 0.095 & \\
\hline $\mathrm{H}_{0}$ : IV are valid (reject if $\mathrm{p}<0.05$ ) & & & $\mathrm{p}=0.5714$ \\
\hline
\end{tabular}


Table 4: Household frequency by average weekly alcohol purchase level

\begin{tabular}{llll}
\hline $\begin{array}{l}\text { Household } \\
\text { alcohol } \\
\text { purchase decile }\end{array}$ & Whole sample (N=2671) & $\begin{array}{l}\text { Households with income } \\
\text { data }(\mathbf{N}=\mathbf{2 1 3 0})\end{array}$ & $\begin{array}{l}\text { Households without } \\
\text { income data } \\
\mathbf{( N = 5 4 1 )}\end{array}$ \\
\hline $\mathbf{1}$ & $256(9.58 \%)$ & $193(9.06 \%)$ & $63(11.65 \%)$ \\
$\mathbf{2}$ & $262(9.81 \%)$ & $208(9.77 \%)$ & $54(9.98 \%)$ \\
$\mathbf{3}$ & $277(10.37 \%)$ & $219(10.28 \%)$ & $58(10.72 \%)$ \\
$\mathbf{4}$ & $260(9.73 \%)$ & $201(9.44 \%)$ & $59(10.91 \%)$ \\
$\mathbf{5}$ & $270(10.11 \%)$ & $219(10.28 \%)$ & $51(9.43 \%)$ \\
$\mathbf{6}$ & $280(10.48 \%)$ & $214(10.05 \%)$ & $66(12.20 \%)$ \\
$\mathbf{7}$ & $275(10.30 \%)$ & $226(10.61 \%)$ & $49(9.06 \%)$ \\
$\mathbf{8}$ & $264(9.88 \%)$ & $219(10.28 \%)$ & $45(8.32 \%)$ \\
$\mathbf{9}$ & $268(10.03 \%)$ & $215(10.09 \%)$ & $53(9.80 \%)$ \\
$\mathbf{1 0}$ & $259(9.70 \%)$ & $216(10.14 \%)$ & $43(7.95 \%)$ \\
& Pearson chi2(9) $=11.15$ & $\operatorname{Pr}=0.265$ & \\
\hline
\end{tabular}

Source: calculated by the authors - based on Kantar Worldpanel data (2008-2010)

\section{Discussion}

Results from all the econometric models show a strong association between households purchasing the greatest numbers of alcohol units per adult and cheap alcohol. Income is not significant in the preferred HT specification. Post-estimation predictions show that the probability of purchasing cheap alcohol increases with total alcohol purchased and is similar across all income groups. A similar pattern is seen for the predicted quantity of cheap alcohol; low income group is not the predominant purchaser of cheap alcohol in any purchasing decile (Figure 1 and Figure 2).

Figure 1: Average predicted probability of purchasing cheap alcohol units $(<£ 0.50)$ within income and decile groups

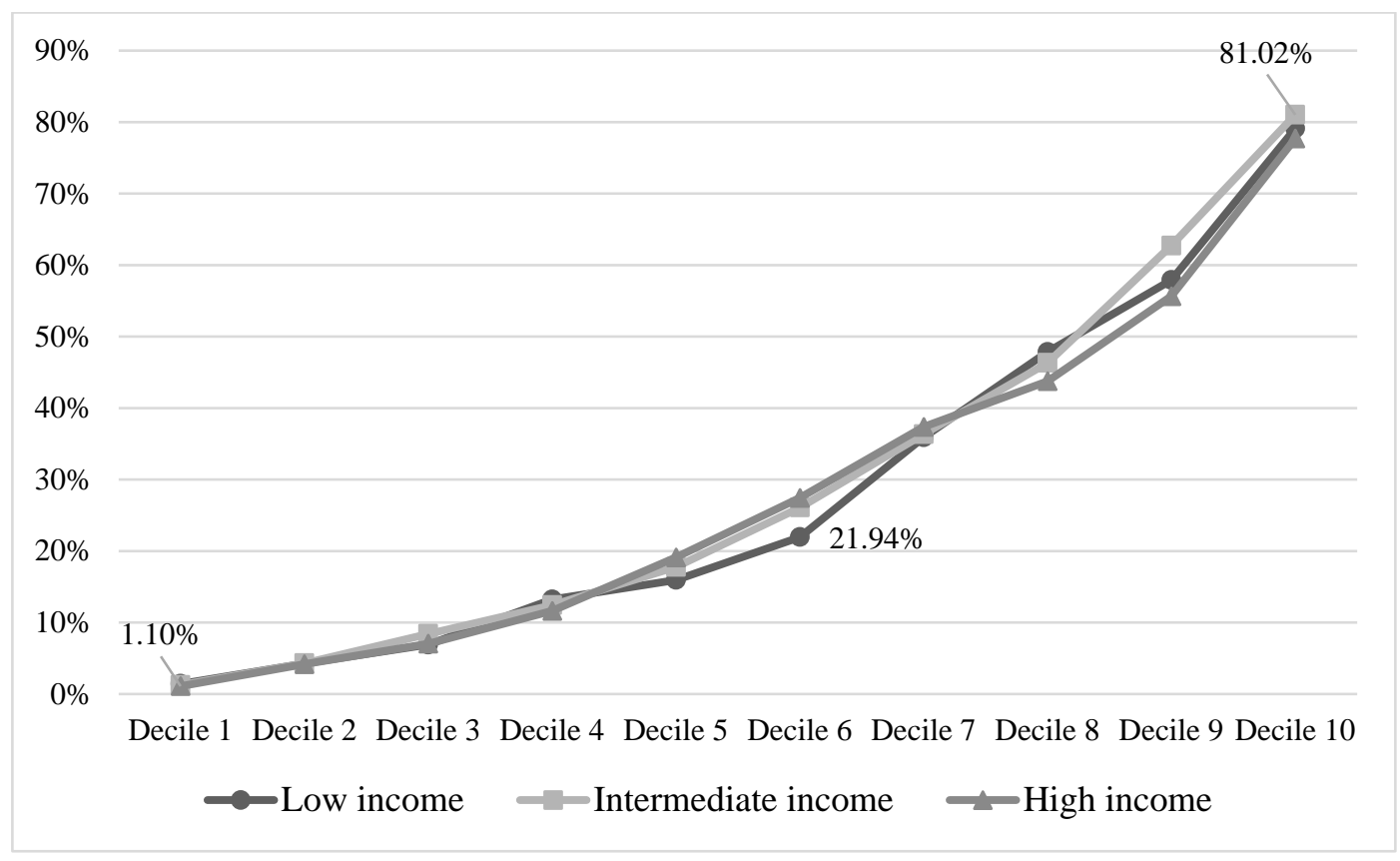


Figure 2: Average predicted quantities of units of cheap alcohol $(<£ 0.50)$ purchased per week per household within income and decile groups

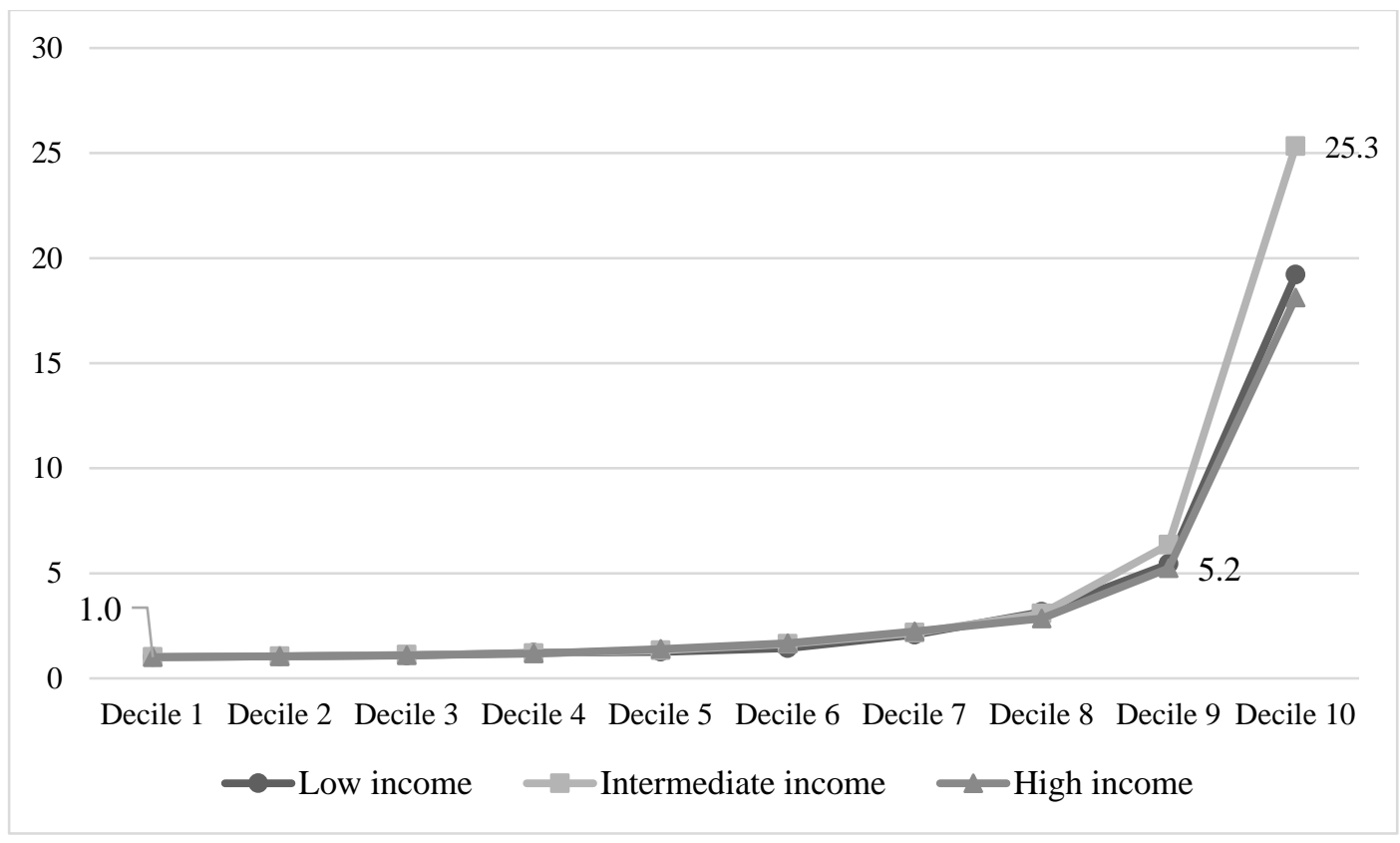

The findings with respect to higher level purchasers of alcohol are consistent with previous studies (Griffith and Leicester, 2010, Ludbrook et al., 2012, Holmes et al., 2014) in respect of purchasing more cheap alcohol and demonstrate that this relationship holds when considering purchasing over an extended period. This is important as cross-sectional data tends to overestimate zero purchasing (Leicester and Oldfield, 2009) and high levels of purchasing may overestimate consumption over a longer period.

The findings of this study also align with other literature which suggests that alcohol consumption is predicted to reduce significantly for the heaviest consumers following the introduction of MUP (Purshouse et al., 2009). Whilst this clearly imposes a cost on them, in terms of loss of utility, hazardous and harmful drinkers are also predicted to benefit the most from the introduction of MUP in terms of reductions of alcohol related harms (Chalmers, 2014, Forsyth et al., 2014, Callinan et al., 2015). The proportionality of using MUP to address alcohol-related harms has been part of the policy debate and legal argument surrounding its introduction in Scotland. The legal argument has recently been determined in favour of its introduction (The Supreme Court, 2017).

The data have also made it possible to explore indicators of social status other than income. In the HT model, income was not significant, and there was a social gradient with respect to occupation such that routine and manual occupations were associated with the highest demand for cheap alcohol. Removing occupation and neighbourhood (Acorn) variables increased the significance of income in the HT models, suggesting that income acts partly as a proxy for other measures of social status and not only as a measure of purchasing power. In other words, this suggests that low socioeconomic status is a significant factor in purchasing cheap alcohol. However, comparing the size of the coefficients, the effect of being in the highest purchasing decile has a far greater effect than social status. The post-estimation predictions from the Tobit model for quantity of cheap alcohol purchased (Figure 2) also indicate that differences only emerge in the highest purchase decile. 
The additional variables available to characterise the alcohol market also offer some interesting insights. Purchasing items on promotion and having more zero weeks of alcohol purchase were both positively associated with demand for cheap alcohol in the HT model, suggesting a pattern of less frequent purchasing of greater quantities. Over a short period, this might indicate stockpiling, but the extended observation period examined here indicates an association with higher purchases of cheap alcohol overall. Preferences for different types of alcohol also have an effect. Compared with table wine, increased frequency of purchasing most other types of alcohol is associated with increased demand for cheap alcohol; the exception is FABs. These associations are plausible as wine has a higher average off-sales price per unit than other categories except for FABs (NHS Health Scotland, 2014a) and FABs account for around 5\% of units sold below 50p (NHS Health Scotland, 2014b).

This study has provided some important insights regarding the market for cheap alcohol. However, some limitations remain and require further research. KWP recruits households partly using census information on geographic area, life stage, household size, age and occupation to achieve national representativeness. Quality control and compliance are regularly monitored. Nevertheless the data has limitations. Alcohol purchases are among the most under-reported categories in KWP (Leicester and Oldfield 2009). This might reflect the method of recording purchases if not all items purchased are taken home and scanned. It may also be the case that such under-recording of alcohol is higher among households purchasing the highest levels of alcohol. Mean levels of purchasing reported and the downward trend between 2008 and 2010 are not replicated in aggregate sales data (NHS Health Scotland, 2014a). The under-reporting problem is common across consumer datasets and the main implication is that the extent of high levels of alcohol purchasing will be underestimated.

There are potential limitations to the approach for identifying household purchase levels. First, the adults in a household may not have an equal share of the alcohol purchased. Secondly, the recommended levels are based on weekly consumption. The data used in this study related to purchases and not consumption. Whilst the analytical approach does attempt to control for this difference in timing by looking at the mean number of purchased units over time, it does not necessarily reflect the true alcohol consumption patterns. It also excludes consumption outside the house and so will underestimate the extent of higher levels of drinking. In relation to potential health effects, this analysis does not identify bingetype consumption, where purchases are consumed over a relatively short period.

The relatively large amount of missing income data was also a potential limitation. However, the issue of potential bias, which is frequently ignored, has been addressed and the missing data does not affect the results reported. The reporting by households of gross income within bands of $£ 10,000$ is also likely to involve a degree of approximation and a loss of information compared with more detailed collection methods but these might simply increase the level of missing data. The grouping of income into 3 categories (low, intermediate and high) reduces the extent to which households might be misallocated (through misreporting their income) as there are only 2 threshold points rather than 7.

The results are an important contribution to the ongoing policy discussion of MUP as they use a longitudinal data set to confirm results relating to income and purchasing level which have been obtained from cross-sectional data. They show that a MUP policy would be well targeted towards the heaviest purchasers of alcohol. Other findings suggest that restrictions on alcohol promotions may also be worth exploring. Although legislation has already been implemented in Scotland to restrict volume based promotions (e.g. buy one get one free; 3 for $£ 10$ ), straightforward price reductions can still be used. These may induce a 
pattern of less frequent purchasing of larger quantities and the results suggest that this may lead to a higher level of purchasing overall.

The findings of this paper should be interpreted in the specific context of Scotland although the general principles underpinning MUP are likely to have wider application. The development of MUP was driven, in part, by increasing sales of cheap off-sales alcohol resulting from price competition between supermarkets, with some products being used as loss leaders to generate footfall. However, the predicted effectiveness of MUP was also supported by economic evidence, including a study using Swedish data (Gruenewald et al., 2006), indicating that this policy could reduce or avoid the 'trading down' to cheaper products that could reduce the effectiveness of tax increases.

The findings here may be of interest to Nordic countries such as Finland and Denmark, which despite very restrictive alcohol legislation, state-controlled retailing of strong alcohol and high prices, have relatively high alcohol consumption levels compared to non-Nordic OECD countries (Ásgeirsdóttir and Gerdtham, 2016). Finland, in particular, has experienced price competition outside the regulated sector, including volume discounting; banning these resulted in price reductions for smaller packages rather than eliminating the volume discounts (WHO, 2013). The application of MUP outside the state regulated sector could provide a solution.

Nordic countries could also review the operation of pricing within state monopolies to focus price increases on the lowest priced products. Canadian provinces also have state alcohol monopolies and can control alcohol prices in a similar manner to MUP. Raising the minimum price level has been shown to reduce consumption and increase health benefits (Stockwell et al., 2012b). However, the relative ease of individuals bringing alcohol from neighbouring countries with lower prices may exacerbate excessive consumption (Ásgeirsdóttir and Gerdtham, 2016) and undermine efforts to control supply.

\section{Acknowledgements}

The authors would like to acknowledge Dr Diane Skåtun, Dr Ramses Abul Naga and Dr Damilola Olajide for providing econometric advice on the paper. The comments and suggestions from two anonymous referees from the Nordic Journal of Health Economics were very useful to improving the content of this paper. The data used in this study were from the Rowett Institute of Nutrition and Health (RINH) Kantar data resource. Core funding from the Chief Scientist Office, Scottish Government Health and Social Care Directorates and the University of Aberdeen is gratefully acknowledged.

\section{Conflict of interest}

The authors declare that they have no competing or potential conflict of interests.

\section{References}

Academy of Medical Sciences. (2004). Calling time: The nation's drinking as a major health issue (pp. 1-45). London: Academy of Medical Sciences.

Acorn. (2013). Understanding consumers and communities. Retrieved November/20, 2014 http://acorn.caci.co.uk/what-is-acorn

Ally, A. K., Meng, Y., Chakraborty, R., Dobson, P. W., Seaton, J. S., Holmes, J., et al. (2014). Alcohol Tax Pass-through across the Product and Price Range: Do Retailers Treat Cheap Alcohol Differently? Addiction, 109(12), 1994-2002. 
Anderson, P., Chisholm, D., and Fuhr, D. C. (2009). Effectiveness and Cost-Effectiveness of Policies and Programmes to Reduce the Harm Caused by Alcohol. The Lancet, 373(9682), 2234-2246.

Ásgeirsdóttir, T., and Gerdtham, U. (2016). Health Behavior in the Nordic Countries. Nordic Journal of Health Economics, 4(1), 28-40.

Baltagi, B. H., Bresson, G., and Pirotte, A. (2003). Fixed Effects, Random Effects or HausmanTaylor?: A Pretest Estimator. Economics Letters, 79(3), 361-369.

Black, H., Gill, J., and Chick, J. (2011). The Price of a Drink: Levels of Consumption and Price Paid per Unit of Alcohol by Edinburgh's Ill Drinkers with a Comparison to Wider Alcohol Sales in Scotland. Addiction, 106(4), 729-736. doi:http://dx.doi.org/10.1111/j.1360-0443.2010.03225.x

Callinan, S., Room, R., Livingston, M., and Jiang, H. (2015). Who Purchases Low-cost Alcohol in Australia? Alcohol and Alcoholism, 50(6), 1-7.

Cameron, A. C., and Trivedi, P. K. (2009). Microeconometrics using Stata (Revised ed). Texas: Stata Press College Station.

Chalmers, J. (2014). Alcohol Minimum Unit Pricing and Socioeconomic Status. The Lancet, 383(9929), 1616-1617.

Chaloupka, F. J., Grossman, M., and Saffer, H. (2002). The Effects of Price on Alcohol Consumption and Alcohol-related Problems. Alcohol Research and Health, 26(1), 22-34.

Crawford, M. J., Parry, A. M., Weston, A. R., Seretis, D., Zauter-Tutt, M., Hussain, A., et al. (2012). Relationship between Price Paid for Off-trade Alcohol, Alcohol Consumption and Income in England: A Cross-sectional Survey. Alcohol \& Alcoholism, 47(6), 738-742. doi:http://dx.doi.org/10.1093/alcalc/ags091

Department of Health. (2016). UK Chief Medical Officers' alcohol guidelines review - Summary of the proposed new guidelines (pp. 1-7). London: Crown copyright.

Elder, R. W., Lawrence, B., Ferguson, A., Naimi, T. S., Brewer, R. D., Chattopadhyay, S. K., et al. (2010). The Effectiveness of Tax Policy Interventions for Reducing Excessive Alcohol Consumption and Related Harms. American Journal of Preventive Medicine, 38(2), 217-229.

Forsyth, A. J., Ellaway, A., and Davidson, N. (2014). How Might the Alcohol Minimum Unit Pricing (MUP) Impact upon Local Off-sales Shops and the Communities which they Serve? Alcohol and Alcoholism (Oxford, Oxfordshire), 49(1), 96-102.

Giesbrecht, N., Wettlaufer, A., Cukier, S., Geddie, G., Gonçalves, A., and Reisdorfer, E. (2016). Do Alcohol Pricing and Availability Policies have Differential Effects on Sub-populations? A Commentary. The International Journal of Alcohol and Drug Research, 5(3), 89-99.

Gillan, E., and Macnaughton, P. (2007). Alcohol - Price, policy and public Health. Report on the findings of the expert workshop by Scottish Health Action on Alcohol Problems (ScHAAP) (pp. 1-60), Edinburgh: ScHAAP.

Griffith, R., and Leicester, A. (2010). The impact of introducing a minimum price on alcohol in Britain (pp. 1-33). London: Institute of Fiscal Studies (IFS).

Gruenewald, P. J., Ponicki, W. R., Holder, H. D., and Romelsjö, A. (2006). Alcohol Prices, Beverage Quality, and the Demand for Alcohol: Quality Substitutions and Price Elasticities. Alcoholism: Clinical and Experimental Research, 30(1), 96-105.

Hobday, M., Gordon, E., Lensvelt, E., Meuleners, L., Liang, W., and Chikritzhs, T. (2016). The Effect of Price Increases on Predicted Alcohol Purchasing Decisions and Choice to Substitute. Addiction Research \& Theory, 24(6), 1-9.

Holmes, J., Meng, Y., Meier, P. S., Brennan, A., Angus, C., Campbell-Burton, A., et al. (2014). Effects of Minimum Unit Pricing for Alcohol on Different Income and Socioeconomic Groups: A Modelling Study. The Lancet, 383(9929), 1655-1664.

Home Office. (2013). Next steps following the consultation on delivering the Government's alcohol strategy (pp. 1-21). London: Crown Copyright. 
Hunt, P., Rabinovich, L., and Baumberg, B. (2011). Preliminary assessment of economic impacts of alcohol pricing policy options in the UK (pp. 1-127). Santa Monica, CA: RAND Corporation.

Leicester, A. (2011). Alcohol pricing and taxation policies (pp. 1-41). London: Institute of Fiscal Studies (IFS).

Leicester, A., and Oldfield, Z. (2009). An analysis of consumer panel data (pp. 1-55). London: Institute of Fiscal Studies (IFS).

Ludbrook, A., Petrie, D., McKenzie, L., and Farrar, S. (2012). Tackling Alcohol Misuse: Purchasing Patterns Affected by Minimum pricing for Alcohol. Applied Health Economics \& Health Policy, 10(1), 51-63. doi:http://dx.doi.org/10.2165/11594840-000000000-00000

NHS Health Scotland. (December 2014a). Alcohol retail sales dataset 1994-2013. Retrieved May/20, 2015, from http://www.healthscotland.com/documents/24485.aspx

NHS Health Scotland. (December 2014b). Off-trade price band distribution data 2009-2013. Retrieved February/17, 2015, from http://www.healthscotland.com/documents/24485.aspx

Office for National Statistics. (2012). Consumer price indices (CPI), September 2012. Retrieved August, 2014, from http://www.ons.gov.uk/ons/publications/re-referencetables.html?edition=tcm\%3A77-260874

Purshouse, R., Meng, Y., Rafia, R., Brennan, A., and Meier, P. (2009). Model-based appraisal of alcohol minimum pricing and off-licensed trade discount bans in Scotland: A Scottish adaptation of the Sheffield Alcohol Policy Model Version 2 (pp. 1-193). Sheffield: University of Sheffield.

Scottish Government. (2012). Changing Scotland's relationship with alcohol: A framework for action (pp. 1-45). Edinburgh: Scottish Government.

Sharma, A., Vandenberg, B., and Hollingsworth, B. (2014). Minimum Pricing of Alcohol versus Volumetric Taxation: Which Policy will Reduce Heavy Consumption without Adversely Affecting Light and Moderate Consumers? PLOS ONE, 9(1), 1-13.

Stockwell, T., Auld, M. C., Zhao, J., and Martin, G. (2012). Does Minimum Pricing Reduce Alcohol Consumption? The Experience of a Canadian Province. Addiction, 107(5), 912-920.

Stockwell, T., Zhao, J., Giesbrecht, N., Macdonald, S., Thomas, G., and Wettlaufer, A. (2012). The Raising of Minimum Alcohol Prices in Saskatchewan, Canada: Impacts on Consumption and Implications for Public Health. American Journal of Public Health, 102(12), 103-110.

Stockwell, T., Zhao, J., Sherk, A., Callaghan, R. C., Macdonald, S., and Gatley, J. (2017). Assessing the Impacts of Saskatchewan's Minimum Alcohol Pricing Regulations on Alcohol-related Crime. Drug and Alcohol Review, 36(4), 492-501.

The Supreme Court (2017). Judgement - Scotch Whisky association and others (Appellants) $v$ the Lord Advocate and another (Respondents) (pp. 1-35). Scotland.

Wagenaar, A. C., Salois, M. J., and Komro, K. A. (2009). Effects of Beverage Alcohol Price and Tax Levels on Drinking: A Meta-analysis of 1003 Estimates from 112 Studies. Addiction, 104(2), 179-190.

Wagenaar, A. C., Tobler, A. L., and Komro, K. A. (2010). Effects of Alcohol Tax and Price Policies on Morbidity and Mortality: A Systematic Review. American Journal of Public Health, 100(11), 2270-2278.

WHO. (2013). Status report on alcohol and health in 35 European countries (pp. 1-178). Copenhagen, Denmark: World Health Organization (WHO).

(C) 2018 by the author(s). This article is an open access article distributed under the terms and conditions of the Creative Commons Attribution license (http://creativecommons.org/licenses/by/4.0/). 